\title{
Sarfaraz modification of king vision video laryngoscope blade
}

\author{
Sarfaraz Ahmad $^{\text {* }}$ \\ Consultant Anaesthesiologist, Paras HMRI Super Speciality Hospital, Patna, India.
}

In the modern era of anaesthesiology practice use of the video laryngoscope to secure the airway is going to be the gold standard method for difficult intubation. Day by day new video laryngoscopes have been launched in the market. ${ }^{1,2}$ Mouth opening requirement and movement at cervical spine become very important while using video laryngoscope in difficult intubation.

I have made a modification in the non-channelled blade of King Vision video laryngoscope, while keeping in mind the requirement of mouth opening and no movement at cervical spine for intubation, by incorporating a nasal airway (size8.0) using durapore 3 inch as shown in Figure 1.

I introduced a gum elastic bougie through the incorporated nasal airway with the blade. As a result, I am able to pass the bougie through vocal cord and after that laryngoscope blade is removed while keeping bougie in place and now the desired endotracheal tube is mounted over the bougie and introduced through the vocal cords, followed by removal of the bougie while keeping endotracheal tube in place. By doing this, I am able to convert the non-channelled blade to the new modified channelled blade while keeping the thickness of blade remain same. Non-channelled blade thickness is less than the original channelled blade. With the help of this modified blade, I am able to easily intubate a patient with minimum mouth

*Correspondence: Sarfaraz Ahmad

E mail: saquasimi2012@gmail.com

https://orcid.org/0000-0002-1339-9482

Received: $13 / 12 / 2019$

Accepted: 26/12/2019

DOI: http:/doi.org/10.4038/slja.v28i1.8528

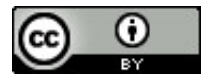

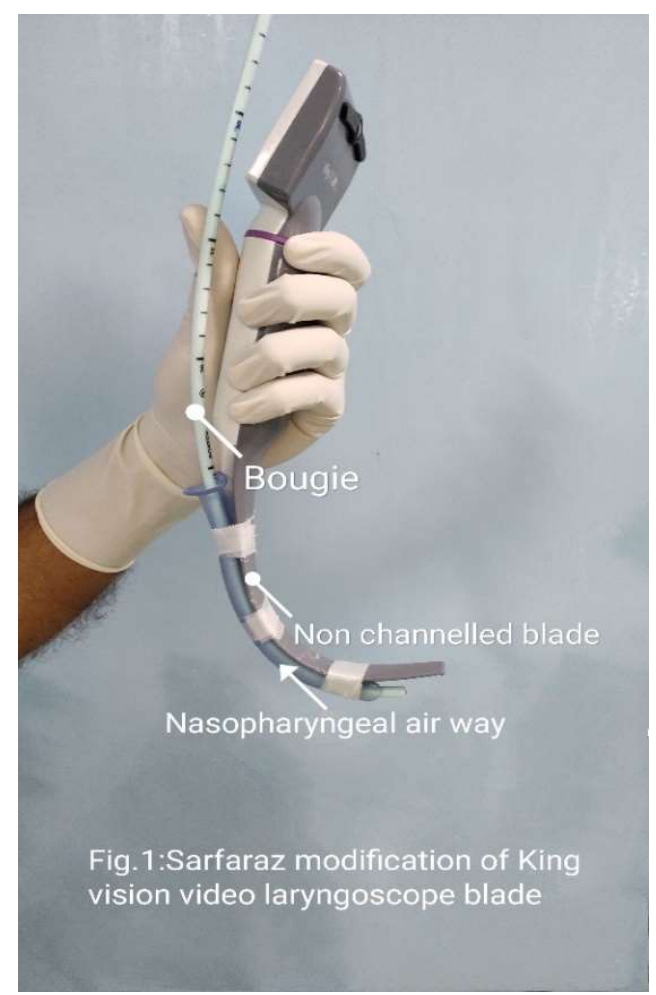

opening of $1.2 \mathrm{~cm}$ and no movement needed at cervical spine.

In circumstances where there are limited resources, where fibreoptic bronchoscope is not available this modified blade was found to be very successful in case of intubation of the immobilised cervical spine, temporomandibular joint ankylosis, post burn contracture of neck, restricted mouth opening and many more difficult airway management situations.

\section{References}

1. Cook T, Pandit J, Wilkes A. Introduction and evaluation of new airway devices. TACC 2012;2:264-8. https://doi.org/10.1016/j.tacc.2012.08.002

2. Cook TM. Novel airway devices: spoilt for choice? Anaesthesia 2003;58:107-10 https://doi.org/10.1046/j.1365-2044.2003.03047.x PMid:12562404 